\title{
Schimmelpilzallergien: Die Diagnostik etabliert sich
}

\section{In der Diagnostik und Therapie von Pilzallergien stehen wir erst am Anfang. Ein Hauptproblem stellt die mangelnde Standardisierung der Allergenextrakte dar. Speziell für den Schimmelpilz Alternaria alternata ist man jetzt einen Schritt weiter: Mit Hilfe eines mono- klonalen Antikörpers kann das Hauptallergen quantifiziert werden.}

Typ-I-Allergien gegen Schimmelpilze, vor allem gegen Aspergillus-Spezies oder Alternaria alternata, sind bei uns nicht selten. Daß aber Angaben über die Häufigkeit zwischen 1 und $30 \%$ schwanken, zeigt die noch bestehende Unsicherheit, eine derartige Allergie auch wirklich einwandfrei diagnostizieren zu können.

Der Grund hierfür liegt in der Heterogenität der für die Diagnose verwendeten Schimmelpilzextrakte: Das Allergenspektrum variiert stark, je nachdem, wie die Pilze kultiviert und die Allergene extrahiert wurden. Die Aussagekraft einer lege artis durchgeführten Diagnostik hängt aber entscheidend von diesen Parametern ab. Nur wenn von Charge zu Charge reproduzierbare Werte hinsichtlich Qualität und Quantität der Allergene gewährleistet ist, kann dem Patienten seine ,Schimmelpilzallergie" attestiert werden.

Welche Schritte die Hersteller solcher Schimmelpilzallergenextrakte tun müssen, um den Allergologen ein adäquates Präparat präsentieren zu können, wurde jetzt am Beispiel von Alternaria alternata gezeigt. Bisher ist es nämlich nicht gelungen, einen international anerkannten Standard für einen Alternaria-alternata-Extrakt zu etablieren. Zwar ist das Hauptallergen Alt a 1 gut charakterisiert und wird bereits als rekombinantes Protein hergestellt, doch gibt es nur wenige Daten über die Mengen an Alt a 1 in Extrakten.

Dies dürfte sich nun ändern. In einer von E. Aden et al. publizierten Arbeit wird über die Entwicklung eines Assays für die Quantifizierung von Alt a 1 berichtet. Dieser Zwei-Site-Bin- dungstest, basierend auf einem Alt a 1spezifischen monoklonalen Antikörper, wurde auf seine Tauglichkeit hinsichtlich der Alt a 1-Bestimmung in Allergenextrakten getestet - eine wichtige Voraussetzung zur Überprüfung der Chargengleichförmigkeit. Gleichzeitig wurde getestet, ob sich eine Korrelation zwischen den gefundenen Alt a 1-Konzentrationen und den quantitativen Pricktests bei 16 Alternaria-sensibilisierten Patienten herstellen ließ.

Die Ergebnisse: Der Alt a 1-spezifische monoklonale Antikörper erwies sich als geeignet für den Zwei-SiteBindungstest zur Quantifizierung des Allergengehaltes. Auch war eine affinitätschromatographische Reinigung von Alt a 1 mit diesem Antikörper möglich. Der Alt a 1-Gehalt in Allergenextrakten beträgt $2,0 \%$ bis $4,7 \%$ vom Gesamtprotein.

Auch die Reaktionen der Alternaria-sensibilisierten Patienten in den quantitativen Pricktests korrelierten gut mit der gefundenen Alt a 1-Konzentration. So verursachte ein Extrakt mit 3,7 $\mu \mathrm{g}$ Alt a 1/ml Quaddelgrößen, die vergleichbar mit den Quaddelgrößen nach Anwendung einer 1\%igen Histamindichlorid-Lösung waren.

Somit ist mit der Entwicklung des Alt a 1-spezifischen monoklonalen Antikörpers ein erster Schritt getan, Alternaria-Extrakte hinsichtlich des Hauptallergens zu quantifizieren - die Basis für eine sichere Diagnostik einer Alternaria-Allergie.

$b k$

Aden E, Weber B, Bossert J, et al.: Standardization of Alternaria alternata: Extraction and quantification of Alt a 1 by using an mAb-based 2-site binding assay. J Allergy Clin Im- 